\title{
Manifestation of wave activity in the upper atmosphere during winter sudden stratospheric warmings
}

\author{
I. V. Medvedeva ${ }^{1,2}$, K. G. Ratovsky ${ }^{1}$ \\ ${ }^{1}$ Institute of Solar-Terrestrial Physics, Siberian Branch, Russian Academy of Sciences, \\ Irkutsk, 664033, Russia \\ ${ }^{2}$ Obukhov Institute of Atmospheric Physics, Russian Academy of Science, Moscow, \\ 119017, Russia \\ E-mail: ivmed@iszf.irk.ru
}

\begin{abstract}
We present the results of studying manifestation of atmospheric wave activity at the heights of the mesopause and ionospheric F2-region over Eastern Siberia, during winter sudden stratospheric warmings in February-March 2016 and February 2017. The study was carried out using experimental data on the rotational temperature of the hydroxyl molecule and on the peak electron density $\mathrm{NmF}$. We revealed a significant increase in the manifestation of the activity of atmospheric waves of different time scales in the upper atmosphere during the SSWs, and found the differences of the SSWs effects for the analysed events.
\end{abstract}

Accepted: 15.09 .2020

DOI: 10.21046/2070-7401-2020-17-6-159-166

\section{Introduction}

The Earth's whole atmosphere is affected by solar, geomagnetic and magnetospheric processes from above and by internal atmospheric waves with various time scales from below. Atmospheric waves can transport energy from the lower to the upper atmosphere and provide the vertical coupling of the atmospheric layers. Winter sudden stratospheric warming (SSW) is one of the most significant phenomena in the lower and middle atmosphere. SSW can cause disturbances in a wide range of atmospheric heights, from the troposphere to the thermosphere, and influence on the upper neutral atmosphere and ionosphere parameters [1-5]. During SSWs, activity of atmospheric waves with different time scales can increase significantly.

In this study, we analyse manifestation of the activity of atmospheric waves of different time scales at the height of the mesopause and F2-region of the ionosphere during minor winter sudden stratospheric warmings in February 2016 and February 2017 and final stratospheric warming in March 2016.

\section{Data and method of analysis}

To estimate manifestations of wave activity at the height of the mesopause, we analysed variability of its temperature, which was derived from the data of spectrometric observations of hydroxyl emission $((6-2), 834 \mathrm{~nm})$. The measurements are carried out at the Institute of Solar-Terrestrial Physics Geophysical Observatory $\left(51.8^{\circ} \mathrm{N}, 103.1^{\circ} \mathrm{E}\right.$, Tory). The $\mathrm{OH}$ emission spectra recorded with 10 -minutes temporal resolution are used to derive the rotational temperature of a hydroxyl molecule which corresponds to the atmospheric temperature at the mesopause height $(\mathrm{OH}$ emission layer maximum is about $87 \mathrm{~km}$ ) [6, 7]. The accuracy of determining the $\mathrm{OH}$ rotational temperature by this method is about $2 \mathrm{~K}$. The measurement methods and the data processing procedures are described in details in [7,8]. 
To investigate manifestations of wave activity in the ionospheric F2-region, we analysed variability in the F2 peak electron density $(\mathrm{NmF} 2)$ obtained from the vertical sounding data of the Irkutsk Digisonde $\left(52.3^{\circ} \mathrm{N}, 104.3^{\circ} \mathrm{E}\right)$. The Digisonde measurement temporal resolution is $15 \mathrm{~min}$.

To analyse the zonal characteristics of the stratosphere over Northern Hemisphere in winter months, we involved the MERRA-2 (Modern ERA-Retrospective Analysis for Research and Applications) reanalysis daily data. To investigate the state of the middle atmosphere within the analyzed region, we used satellite temperature data from MLS Aura (v.3.3). To estimate geomagnetic activity level, we used $K_{p}$ indices from WDC-A in Boulder, Colorado.

Atmospheric waves with different time scales (planetary waves, tides, internal gravity waves (IGW)) propagating at the mesosphere-lower thermosphere (MLT), result to the mesopause temperature variability. Thus, day-to-day mesopause temperature variability is mainly caused by the planetary waves (PW) propagation. Diurnal temperature variability is mainly caused by tides and internal gravity waves (IGWs). To analyse manifestation of the PWs activity at the mesopause, we calculated temperature residuals after subtracting regular seasonal variations from a series of nightly averaged experimental data, using the least square fitting. As a characteristic of the diurnal temperature variability, we use its standard deviation from the average-night temperature. In detail, the method is described in $[9,10]$.

A NmF2 disturbance was calculated as a deviation of the observed value $\left(\mathrm{NmF}_{\mathrm{OBS}}\right)$ from the 27 -day running median $\left(\mathrm{NmF} 2_{\mathrm{MED}}\right)$. The variability is considered as the root mean square of $\mathrm{NmF} 2$ disturbances: $\sigma_{R} \mathrm{NmF} 2=\left(<\Delta_{R} \mathrm{NmF} 2^{2}>\right)^{1 / 2}$.

\section{Results and discussion}

Winter sudden stratospheric warmings in 2016 and 2017 caused significant disturbances in temperature and dynamics of the Northern Hemisphere stratosphere. Figure 1 presents variations in the zonal stratosphere parameters at the $10 \mathrm{hPa}$ level $(\sim 32 \mathrm{~km})$ from the MERRA-2 reanalysis: zonal mean $\left(60-90^{\circ} \mathrm{N}\right)$ temperature (a), zonal mean zonal wind at $60^{\circ} \mathrm{N}(\mathrm{b})$, and variations in the stratospheric temperature at $10 \mathrm{hPa}$ over Irkutsk from the MLS Aura data (c) for 15 January - 15 April 2016. Since the end of January 2016, the disturbances in the temperature and dynamics of the middle atmosphere over the Northern Hemisphere (increase in the zonal temperature, weakening in the zonal mean zonal wind) had been observed, and this resulted to the development of the minor winter sudden stratospheric warming in early February. The second SSW started to develop from the second half of February. On March 5, 2016, the zonal mean wind reversal occurred (figure 1, blue vertical lines), winter circumpolar vortex was destroyed and was no longer recovered. Therefore, in early March 2016, the final stratospheric warming had developed; and this led to early seasonal transition of the middle atmosphere circulation. Over the analysed region, the stratospheric temperature in February-March 2016 was characterized by strong variations, in particular, the temperature at $10 \mathrm{hPa}$ during the minor SSW increased by $\sim 50 \mathrm{~K}$ on February 5 (figure 1c, orange line). Thus, the temperature at $10 \mathrm{hPa}$ during the minor SSW increased by $\sim 50 \mathrm{~K}$ on February 5 (figure 1c, orange line).

Figure 2 shows the same as figure 1 but for 1.01-15.03.2017 time interval. In late January and early February 2017, strong disturbances also occurred in the middle atmosphere over the Northern Hemisphere (figure 2a, b); there were increase in the temperature (a), and weakening of the zonal mean zonal wind by $\sim 50 \mathrm{~m} / \mathrm{s}$ without reversal (b). Thus, in February 2017 a minor SSW occurred. Over the analyzed region, in late January - February 2017 there were observed significant variations in the stratospheric temperature at $10 \mathrm{hPa}$ (figure $2 \mathrm{c}$ ).

Using the method for estimating atmospheric and ionospheric variability described above and in [10], the manifestation of activity of atmospheric waves of different time scales (planetary waves, tides, internal gravitational waves) at the heights of the mesopause and F2-region of the ionosphere during the SSWs was analyzed. The obtained values were compared to the seasonal average values for each month, obtained from long-term measurements in 2008-2015 (tables 1 and 2).

Using the method for estimating atmospheric and ionospheric variability described above and in [10], the manifestation of activity of atmospheric waves of different time scales (planetary waves, tides, internal gravitational waves) at the heights of the mesopause and F2-region of the ionosphere during the SSWs was analyzed. The obtained values were compared to the seasonal average values for each month, obtained from long-term measurements in 2008-2015 (tables 1 and 2). 

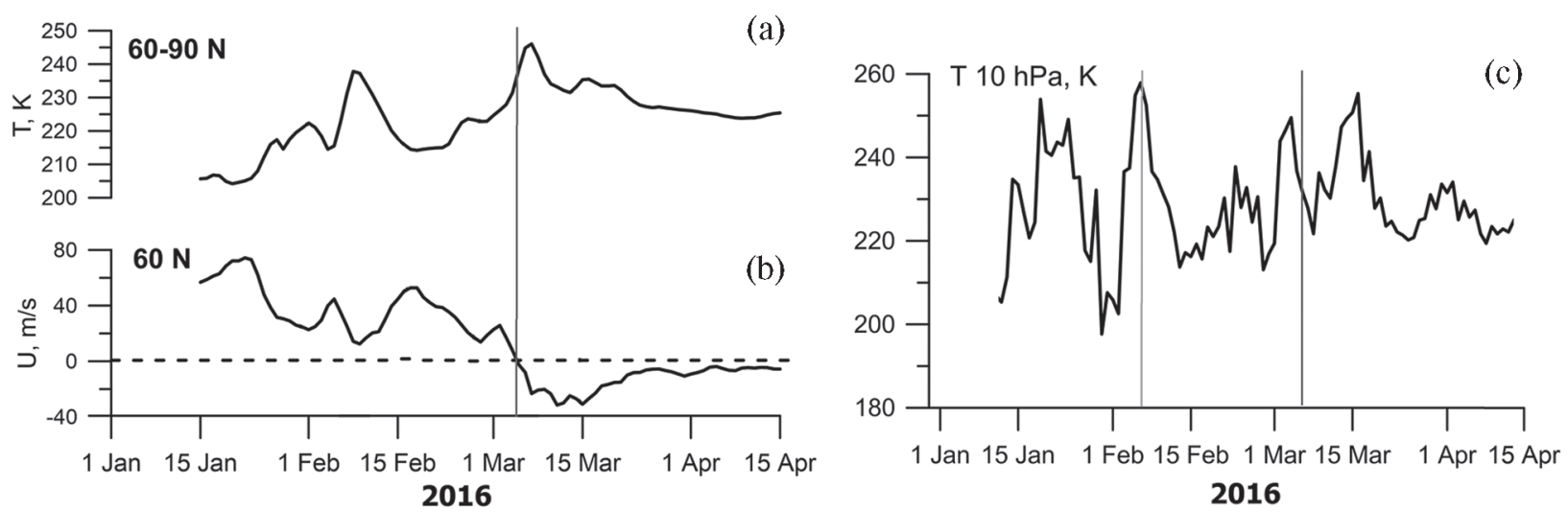

Figure 1. Variations in the zonal stratosphere parameters at the $10 \mathrm{hPa}$ level $(\sim 32 \mathrm{~km})$ from the MERRA-2 reanalysis: zonal mean $\left(60-90^{\circ} \mathrm{N}\right)$ temperature (a) and zonal mean zonal wind at $60^{\circ} \mathrm{N}(\mathrm{b})$, and variations in the stratospheric temperature at $10 \mathrm{hPa}$ over Irkutsk from the MLS Aura data (c) for 15 January - 15 April 2016. Vertical orange line indicates the day of peak warming at $10 \mathrm{hPa}(\sim 32 \mathrm{~km})$ over analyzed region for the minor SSW. Vertical blue line marks the day of zonal mean zonal wind reversal for the final warming.
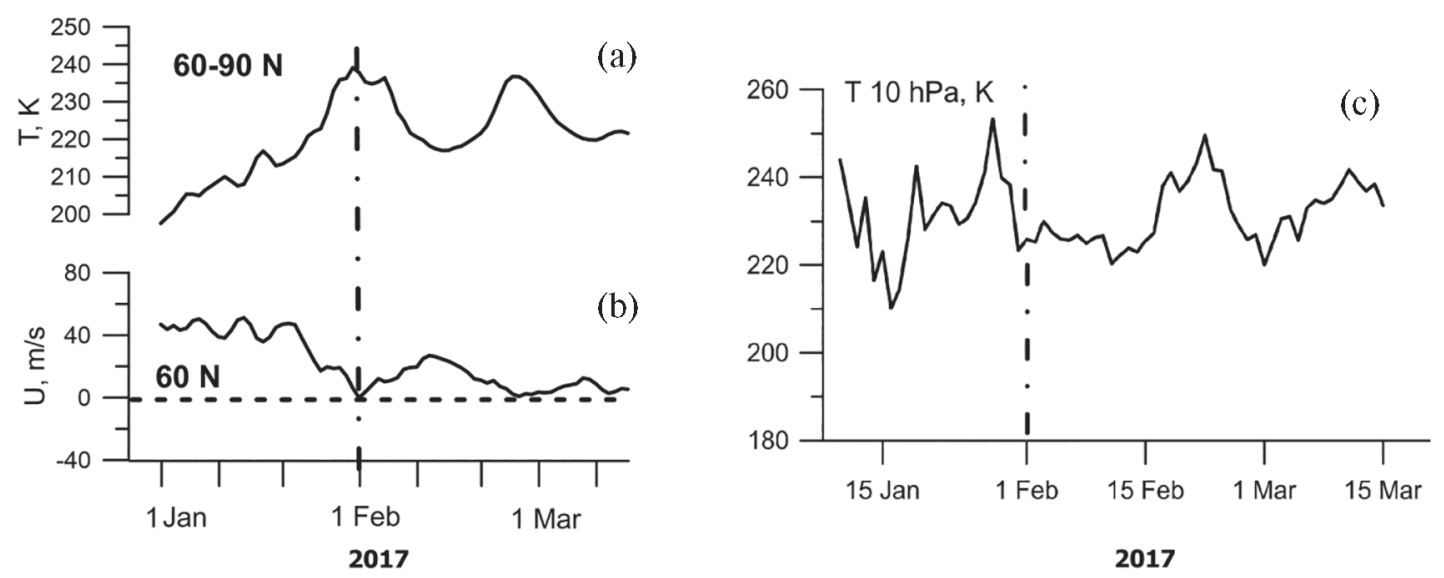

Figure 2. Variations in the zonal stratosphere parameters at the $10 \mathrm{hPa}$ level $(\sim 32 \mathrm{~km})$ from the MERRA-2 reanalysis: zonal mean $\left(60-90^{\circ} \mathrm{N}\right)$ temperature (a) and zonal mean zonal wind at $60^{\circ} \mathrm{N}$ (b) for 1 January 15 March 2017, and variations in the stratospheric temperature at $10 \mathrm{hPa}$ over Irkutsk from the MLS Aura data (c) for 15 January - 15 March 2017. Vertical dashed-dotted line marks the peak of the 2017 SSW.

Table 1. Averaged for 2008-2015 values of the mesopause temperature variability (degrees of $\mathrm{K}$ ) due to activity of the atmospheric waves with various time scales

\begin{tabular}{lccc}
\hline Month & $\begin{array}{c}\text { Planetary } \\
\text { Waves }\end{array}$ & Tides & IGW \\
\hline December & 10.8 & 4.6 & 3.1 \\
January & 11 & 4.7 & 3.1 \\
February & 8.6 & 4.5 & 2.6 \\
\hline
\end{tabular}

Table 2. Averaged for 2008-2015 values of the NmF2 variability $(\%)$ due to activity of the atmospheric waves with various time scales

\begin{tabular}{lcccccc}
\hline Month & \multicolumn{2}{c}{$\begin{array}{c}\text { Planetary } \\
\text { Waves }\end{array}$} & \multicolumn{2}{c}{ Tides } & \multicolumn{2}{c}{ IGW } \\
\cline { 2 - 7 } & Day & Night & Day & Night & Day & Night \\
\hline December & 14.1 & 20.1 & 12.5 & 15.4 & 11.6 & 11.2 \\
January & 14.0 & 17.8 & 12.7 & 16.5 & 11.1 & 11.2 \\
February & 14.3 & 17.6 & 11.4 & 15.9 & 8.9 & 10.0 \\
\hline
\end{tabular}

Figure 3 presents variations in the mesopause temperature residuals after subtracting the seasonal variations for 7 January - 15 April 2016. That day-to-day mesopause temperature variability is caused by planetary waves activity. Figure 4 shows the mesopause temperature variability caused by the tidal (top) and IGW (bottom) activities for 1 February-31 March 2016. Vertical orange line indicates the day of peak warming at $10 \mathrm{hPa}(\sim 32 \mathrm{~km})$ over analyzed region for minor SSW (5 February). Vertical blue line marks the day of zonal mean zonal wind reversal for final warming (5 March).

The calculated values of the mesopause temperature variability were compared with averaged seasonal ones given in table 1 . The comparison revealed a significant intensification in the activity of wave 
processes at the mesopause height during the minor SSW in February and final stratospheric warming in March 2016. In early February, an increase in the mesopause temperature variability compared to averaged level was up to $\sim 200 \%$ for activity of tides and planetary waves and up to $\sim 500 \%$ for IGWs activity. In late February and early March, a similar increase was up to $\sim 200 \%$ for activity of tides and IGWs. On March 15-17, an increase in the activity of tides and planetary waves was up to 200\% (figure 3, 4).

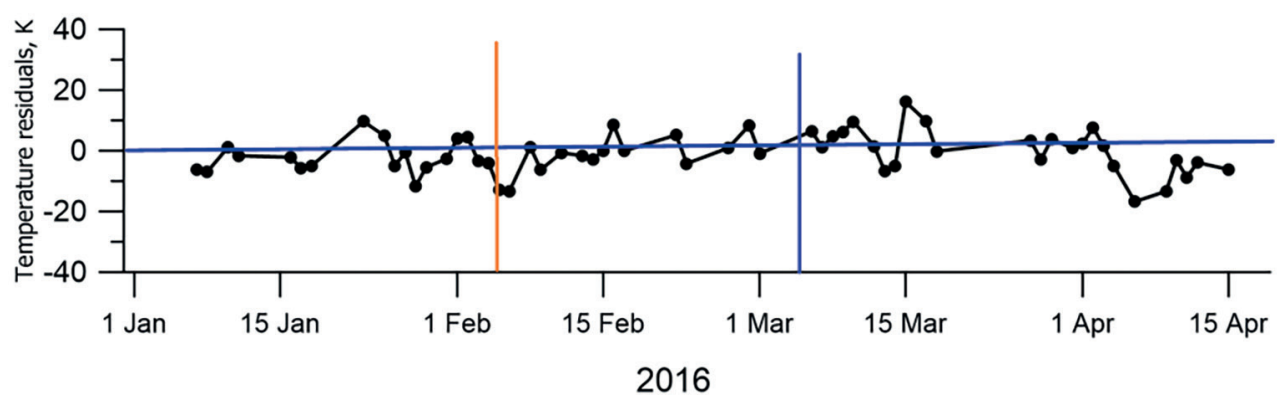

Figure 3. Mesopause temperature residuals after subtracting seasonal variations for 7 January - 15 April 2016. Vertical orange line indicates the day of peak warming at $10 \mathrm{hPa}(\sim 32 \mathrm{~km})$ over analyzed region for minor SSW. Vertical blue line marks the day of zonal mean zonal wind reversal for final stratospheric warming.

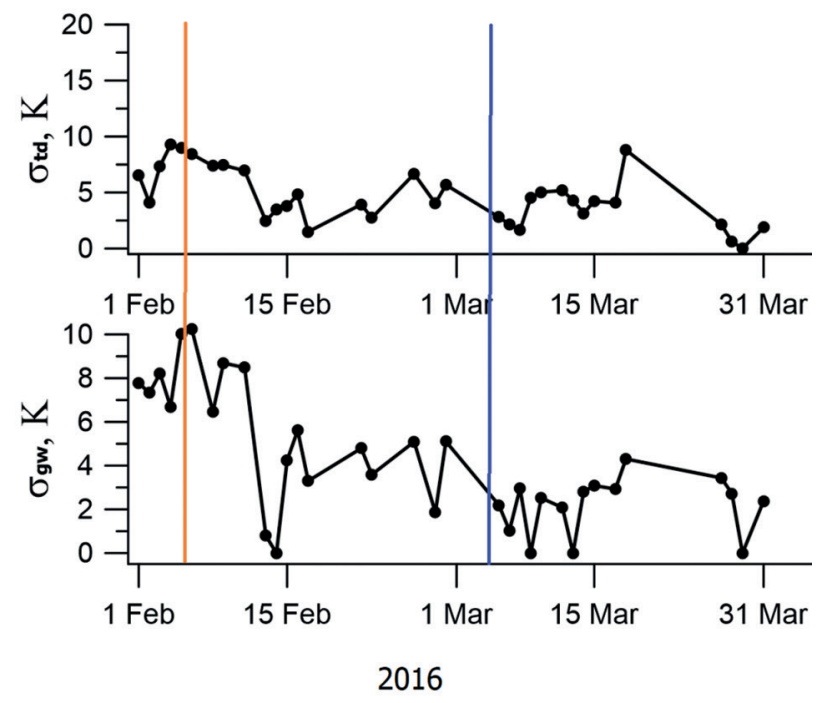

Figure 4. Mesopause temperature variability caused by tides (top), and IGWs (bottom) for 1 February31 March 2016.

Figure 5 shows variations in the peak electron density in January-March 2016: the dynamics of average daytime (10-14 LT) and average nighttime (22-02 LT) NmF2 values and their medians, as well as the dynamics of daytime and nighttime NmF2 disturbances in the 91-day interval (January $01-$ March 31 2016). The vertical lines mark February SSW (Feb 05, DoY 36) and March SSW (Mar 05, DoY 65). The bottom panel shows variations in geomagnetic activity (with daily $K_{p}>20$ marking geomagnetically disturbed conditions). During the SSWs in February and March 2016, the wave-like disturbances are clearly visible in the daytime and nighttime $\Delta \mathrm{NmF} 2$ variations (figure 5 , dotted square). To clarify the nature of these disturbances, the $\Delta \mathrm{NmF} 2$ variations were compared with solar activity. The comparison revealed their high correlation in February and the absence of correlation in March. Thus, the wave-like disturbances in $\Delta \mathrm{NmF} 2$ in February can be explained by solar activity influence, while the $\Delta \mathrm{NmF} 2$ disturbances in March 2016 can be caused by the combined influence of the final SSW and geomagnetic activity.

An analysis of short-period ionospheric disturbances revealed the following SSW associated effects. Figure 6 demonstrates variations in $\Delta \mathrm{NmF} 2$ in the mid-period part (tidal range, $8 \leqslant T \leqslant 24 \mathrm{hrs}$ ), and short-period part (IGWs range, $T<8$ hrs on February 1-9 (left) and March 1-9 (right). The beginning of day is local midnight. Bold solid horizontal lines mark mean seasonal values of the $\Delta \mathrm{NmF} 2$ root-mean-square in the considered bands. On February 5-7, when the geomagnetic conditions 
were quiet, the $\Delta \mathrm{NmF} 2$ positive disturbances were mainly manifested in the tidal range (figure 6). The maximum positive $\Delta \mathrm{NmF} 2$ value in the tidal range was $\sim 2.5$ times higher than mean seasonal value obtained for the February night period (table 2). Note, that the increase in tidal components during SSW was considered as an ionospheric response to SSW in recent studies [3]. During the final stratospheric warming in March 2016, the disturbances in NmF2 were similar to the observed in the early February (figure 6). Under quiet geomagnetic conditions (March 4-6), the positive NmF2 disturbances were observed mainly in the tidal range. However, the amplitude of these disturbances was much less than in February.

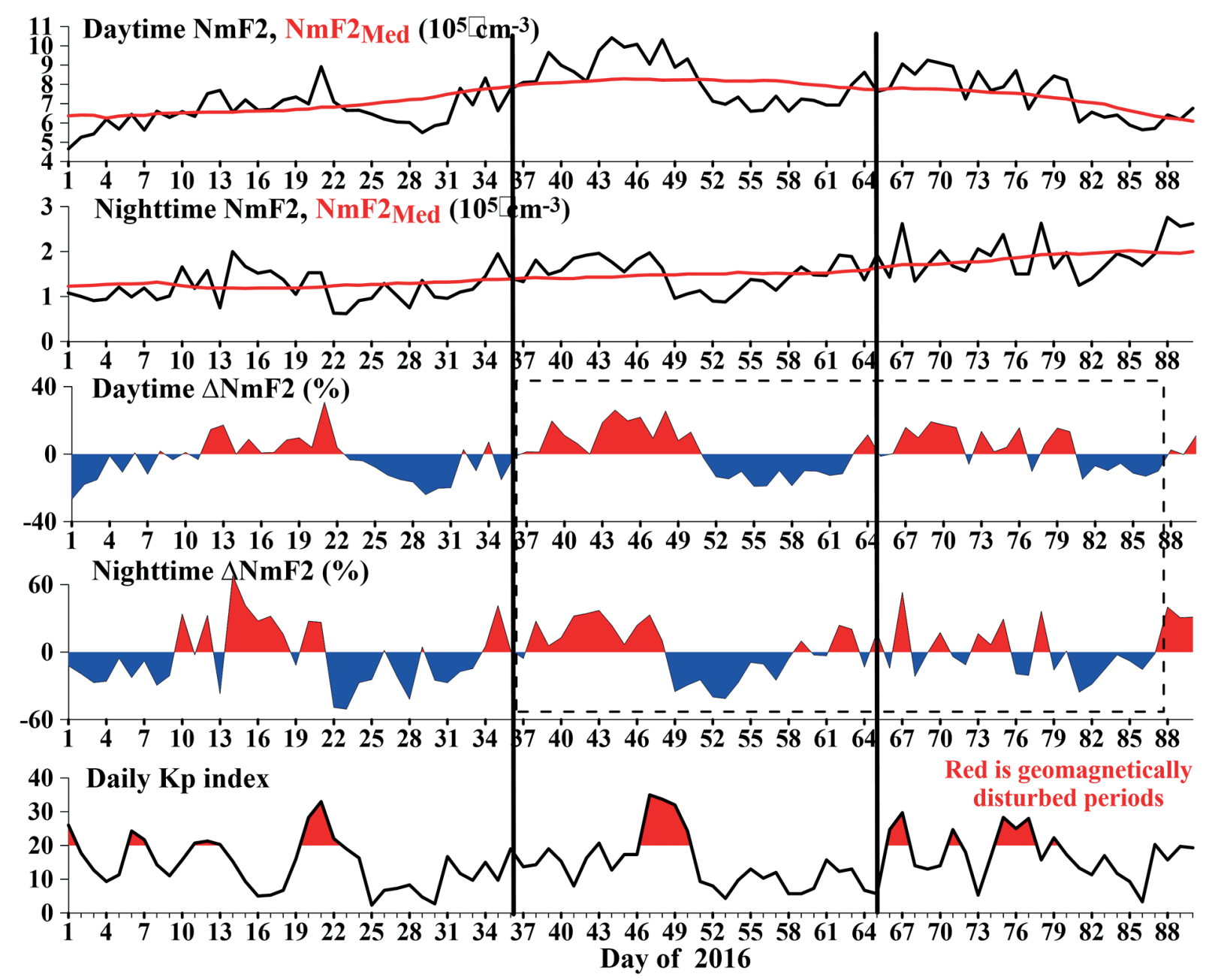

Figure 5. From top to bottom: Dynamics of average daytime (10-14 LT) and average nighttime (22-02 LT) $\mathrm{NmF} 2$ values and their medians, as well as the dynamics of daytime and nighttime NmF2 disturbances in the 91-day interval (days of the year 1-90, January-March) including 2016 SSWs. Vertical lines mark February SSW (Feb 05, DoY 36) and March SSW (Mar 05, DoY 65). The bottom panel shows variations in geomagnetic activity (with daily $K_{p}>20$ marking geomagnetically disturbed conditions).

Figure 7 shows variations in the mesopause temperature residuals after subtracting seasonal variations for 1 January - 15 March 2017. Figure 8 presents the mesopause temperature variability due to activity of tides (upper) and IGWs (bottom) for 1 January - 28 February 2017. Vertical lines mark the peak of the 2017 SSW (01.02.2017). Comparison with averaged seasonal values of the mesopause temperature variability (table 1) revealed, that, in contrary with the SSW 2016, the most significant effects for the SSW 2017 at the mesopause heights were observed in increase in the day-to-day temperature variability due to the influence of planetary waves: up to $250 \%$ (figure 7). Positive disturbances occurred during the SSW development, while negative ones occurred during the period of the SSW maximum. Temperature variability caused by tides did not increased sufficiently; caused by IGWs intensified to $\sim 150 \%$ (figure 8 ). 

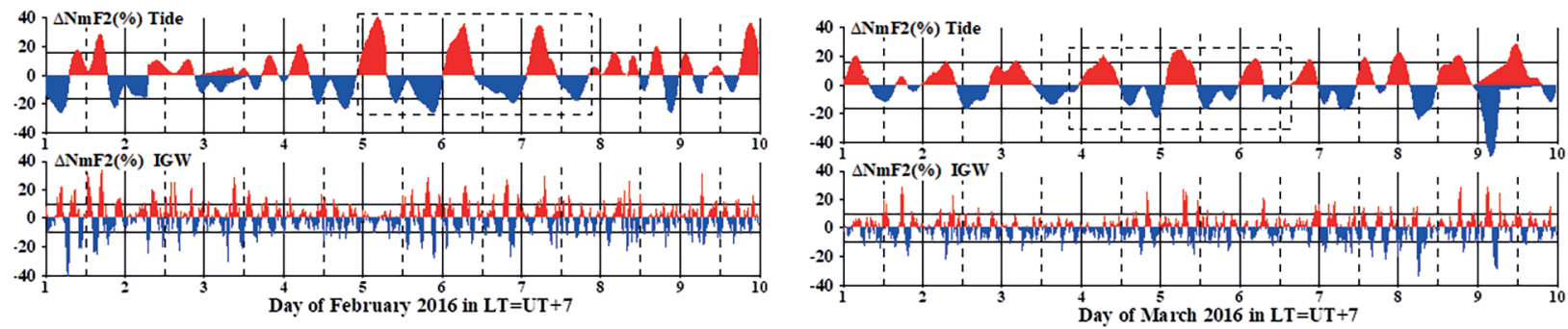

Figure 6. Variations in $\triangle \mathrm{NmF} 2$ in the mid-period part (tidal range, $8 \leqslant T \leqslant 24 \mathrm{hrs}$ ), and short-period part (IGWs range, $T<8 \mathrm{hrs}$ ) on February 1-9 (left) and March 1-9 (right). The beginning of day is local midnight. Bold solid horizontal lines mark mean seasonal values of the $\Delta \mathrm{NmF} 2$ root-mean-square in the considered bands.

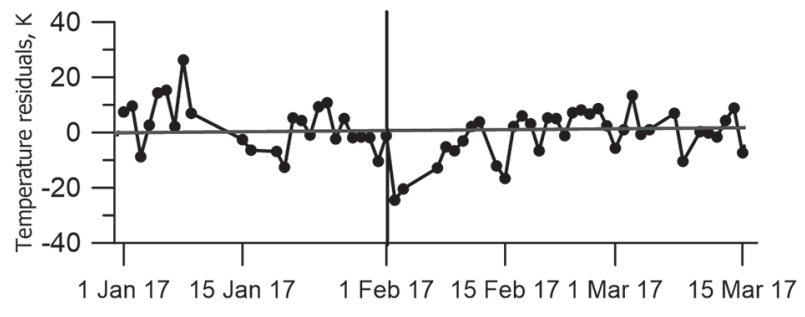

Figure 7. Mesopause temperature residuals after subtracting seasonal variations for 1 January - 15 March 2017. Vertical line indicates the peak of the 2017 SSW.

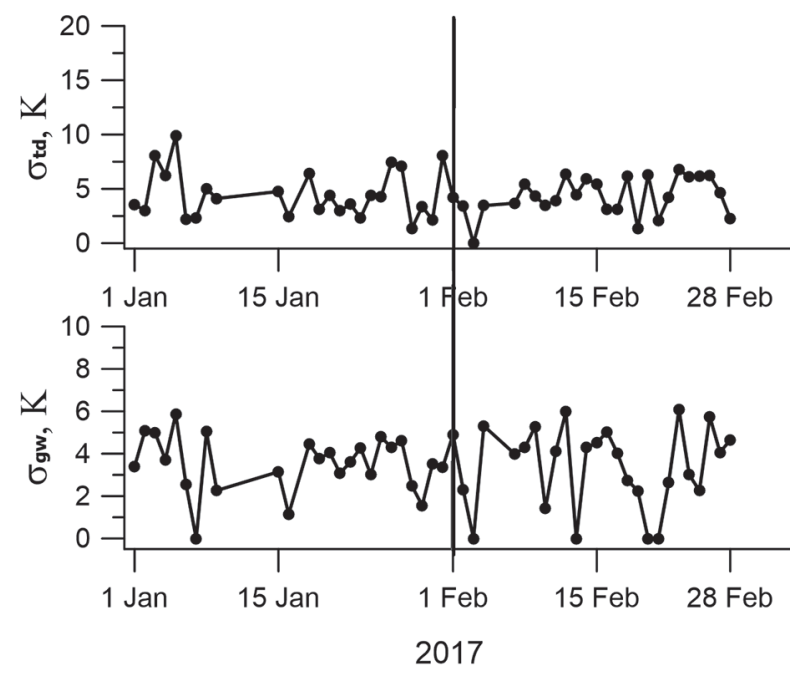

Figure 8. Mesopause temperature variability caused by tides (upper), and IGWs (bottom) for 1 January - 28 February March 2017. Vertical line indicates the peak of the 2017 SSW.

Figure 9 demonstrates behavior of the ionospheric variability during the SSW 2017: the dynamics of average daytime (10-14 LT) and average nighttime (22-02 LT) NmF2 values and their medians, as well as the dynamics of daytime and nighttime NmF2 disturbances in the 91-day interval (days of the year 1-90, January - March). The vertical line indicates the peak of the $2017 \mathrm{SSW}$. The bottom panel shows variations in geomagnetic activity (with daily $K_{p}>20$ marking geomagnetically disturbed conditions). In the variations in daytime $\Delta \mathrm{NmF} 2$ and nighttime $\Delta \mathrm{NmF} 2$ in February and March 2017, after the peak of the SSW, wave-like disturbances occurred (figure 9, dotted square). These disturbances were more pronounced in daytime $\Delta \mathrm{NmF} 2$ variations. The revealed large-scale daily disturbance started 21 days after the SSW peak and lasted for 22 days. Probably, these wave-like disturbances were associated with the SSW effect, but this connection is not obvious due to the large time delay between the SSW peak and the disturbance beginning. An analysis of short-period ionospheric disturbances over a 10-day interval in February 2017 did not reveal SSW associated ionospheric effects.

Thus, the main effect of the minor and final SSWs in February-March 2016 both at the mesopause heights and in the ionospheric F2-region, was in the intensifying the short period variability of the mesopause temperature (mainly due to IGWs activity) and of the peak electron density (mainly due to the tides). During the SSW 2017, at the heights of the mesopause there were increase in planetare waves activity up to $\sim 250 \%$. In the F2 region of the ionosphere, the wave-like disturbances occurred in the $\Delta \mathrm{NmF} 2$ variations 21 days after the SSW peak. Probably, these wave-like disturbances were associated with the SSW effect, but this connection is not obvious due to the large time delay between the SSW peak and the disturbance beginning. An analysis of short-period ionospheric variability over a 10-day interval in February 2017 did not reveal SSW associated ionospheric effects. Thus, in the me- 
sopause heights, a clear response to all the analyzed SSW events was observed. For the SSWs in 2016, this response was the similar as in the ionosphere (intensification in the manifestation of the shortperiod waves). The observed effects can be caused by intensification of the atmospheric wave activity due to the SSWs. The differences in the manifestation of the analyzed SSW in the upper atmosphere can be caused by differences in the dynamics of the underlying atmosphere.
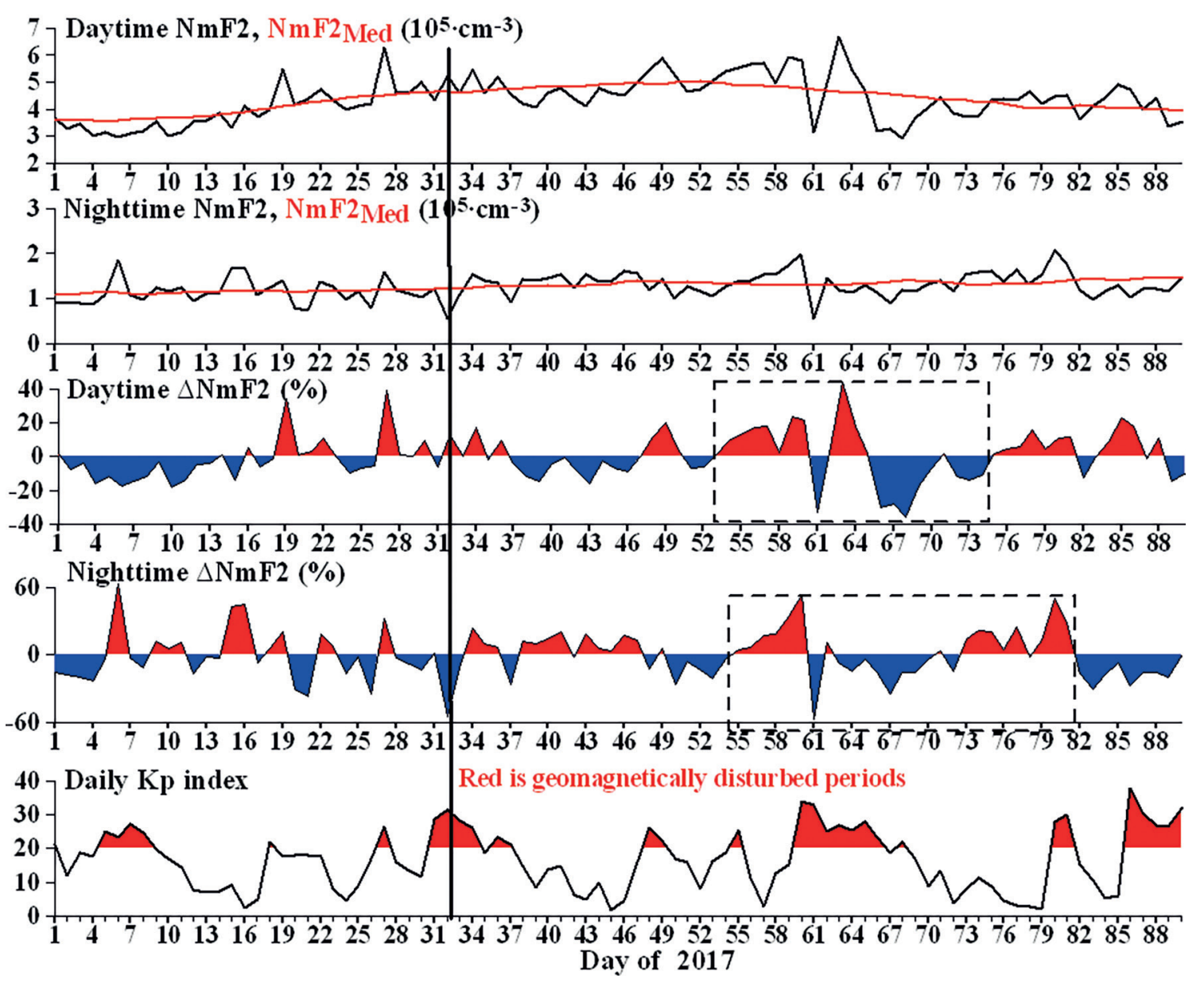

Figure 9. From top to bottom: Dynamics of average daytime (10-14 LT) and average nighttime (22-02 LT) $\mathrm{NmF} 2$ values and their medians, as well as the dynamics of daytime and nighttime NmF2 disturbances in the 91-day interval (days of the year 1-90, January - March) for the SSW 2017. Vertical line indicates the peak of the $2017 \mathrm{SSW}$. The bottom panel shows variations in geomagnetic activity (with daily $K_{p}>20$ marking geomagnetically disturbed conditions).

\section{Conclusions}

We investigated manifestation of the activity of atmospheric waves of various time scales at the heights of the mesopause and ionospheric F2-region during the periods of minor sudden stratospheric warmings in February 2016 and February 2017, and of the final SSW in March 2016. The analysis is based on the experimental data on the rotational temperature of the hydroxyl molecule and on the peak electron density NmF2.

We revealed that at the mesopause height, the clear response to the SSW occurred during the all the analyzed events, however, its nature differed significantly. For the SSWs in February and March 2016, the common features of the manifestation of wave activity in the mesopause and the F2 region were revealed. The main effect of the minor and final SSWs in February-March 2016 both at the mesopause heights and in the ionospheric F2-region, was in the intensifying the short period variability of the mesopause temperature (mainly due to IGWs activity) and the peak electron density (mainly due to the tides). The most significant effect of the SSW 2017 at the heights of the mesopause was in increase in planetary waves activity up to $\sim 250 \%$. In the F2 region of the ionosphere, the wavelike disturbances occurred in the $\Delta \mathrm{NmF} 2$ variations 21 days after the SSW 2017 peak. Probably, these 
wave-like disturbances were associated with the SSW effect, but this connection is not obvious due to the large time delay between the SSW peak and the disturbance beginning. An analysis of short-period ionospheric disturbances over a 10-day interval in February 2017 did not reveal SSW associated ionospheric effects.

\section{Acknowledgements}

This study was supported by the Grant of the Russian Science Foundation (Project No. 18-17-00042). Experimental data recorded by the equipment of Center for Common Use «Angara» (http://ckp-rf.ru/ ckp/3056/) obtained with budgetary funding of Basic Research program II.16 were used. We acknowledge the AURA team, Global Modelling and Assimilation Office (GMAO) (http://acdb-ext.gsfc.nasa. gov/Data_services/met/ann_data.html) and the World Data Center WDC-A in Boulder, Colorado for providing access to the data.

\section{References}

[1] Yasyukevich A.S., Variations in Ionospheric Peak Electron Density During Sudden Stratospheric Warmings in the Arctic Region, J. Geophysical Research: Space Physics, 2018, Vol. 123(4), pp. 3027-3038.

[2] Pedatella N. M., Maute A., Impact of the semidiurnal lunar tide on the midlatitude thermospheric wind and ionosphere during sudden stratosphere warmings, J. Geophysical Research: Space Physics, 2015, Vol. 120(10), pp. 10740-10753, DOI: 10.1002/2015JA021986.

[3] Medvedeva I. V., Semenov A. I., Pogoreltsev A. I., Tatarnikov A.V., Influence of sudden stratospheric warming on the mesosphere/lower thermosphere from the hydroxyl emission observations and numerical simulations, J. Atmospheric and Solar-Terrestrial Physics, 2019, Vol. 187, pp. $22-32$.

[4] Polekh N. M., Chernigovskaya M.A., Yakovleva O.E., On the formation of the F1 layer during sudden stratospheric warming events, Solar-Terrestrial Physics, 2019, Vol.5(3), pp. 117-127, DOI: 10.12737/ szf-53201914.

[5] Klimenko M.V., Klimenko V.V., Bessarab F. S., Korenkov Y.N., Liu H., Goncharenko L.P., Tolstikov M. V., Study of the thermospheric and ionospheric response to the 2009 sudden stratospheric warming using TIME-GCM and GSM TIP models: First results, J. Geophysical Research: Space Physics, 2015, Vol. 120, pp. 7873-7888.

[6] Baker D.J., Stair A.T., Rocket measurements of the altitude distribution of the hydroxyl airglow, Physica Scripta, 1988, Vol. 37(4), pp. 611-622.

[7] Khomich V.Yu., Semenov A. I., Shefov N. N., Airglow as an indicator of upper atmospheric structure and dynamics, Berlin: Springer-Verlag, 2008, 739 p.

[8] Perminov V. I., Shefov N. N., Semenov A. I., On rotational temperature of the hydroxyl emission, Geomagnetism and Aeronomy, Vol. 47(6), pp. 756-763.

[9] Perminov V. I., Semenov A. I., Medvedeva I.V., Zheleznov Yu.A., Variability of mesopause temperature from the hydroxyl airglow observations over midlatitudinal sites, Zvenigorod and Tory, Russia, Advances Space Research, 2014, Vol. 54, pp. 2511-2517.

[10] Medvedeva I., Ratovsky K., Studying atmospheric and ionospheric variability from long-term spectrometric and radio sounding measurements, J. Geophysical Research: Space Physics, 2015, V. 120(6), pp. 5151-5159. 